Bayero Journal of Pure and Applied Sciences, 11(1): 308 - 314

ISSN 2006 - 6996

\title{
CALCULATION OF REACTIONS CROSS SECTION FOR PROTON-INDUCED NUCLEAR REACTIONS ON IODINE-127 ISOTOPE
}

\author{
Idris Ahmad, Fatima Salman Koki, and Yahaya Ibrahim Yola \\ Department of Physics \\ Faculty of Physical Science, \\ Bayero University, Kano, P.M.B. 3011, Kano-Nigeria \\ manidris37@yahoo.com
}

\begin{abstract}
Radioisotope production for nuclear medicine is important because of its common use in tomography devices. Both single photon emissions computed tomography (SPECT) and positron emission tomography (PET) is used for diagnosis in nuclear medicine. In this work, we have calculated the reaction cross section and investigated the excitation functions for the formation of ${ }^{127,126,125} I,{ }^{126,127,128} \mathrm{Xe},{ }^{126,125} \mathrm{Te}$ isotopes in the interactions of proton particle with the nucleus of the iodine-127 isotope. The analysis shows that there is $a$ variation of interaction cross-section with a variation of energy of the incident particle. The result shows that the plots of the ${ }^{127} I(p, n g)$, and ${ }^{127} I(p, 2 n g)$ graphs have full excitation curve. The productions confirm the presence of Xenon-127 and Xenon-126 isotopes are possible at the energy range of 0 to $30 \mathrm{MeV}$ from the iodine-127 nucleus.

Keywords: Cross-Section; Excitation function; Nuclear Reaction; Radioisotope; Statistical Multistep Reaction
\end{abstract}

\section{INTRODUCTION}

At present day, radioisotope production for nuclear medicine is important because of its common use in tomography devices. Both single photon emissions computed tomography (SPECT) and positron emission tomography (PET) is used for diagnosis in nuclear medicine(Ahmad and Koki, 2017). In particular, the radionuclide of iodine is used for these purposes. Therefore, these radionuclides play an important role in medical applications and research. For example, Gamma- emitted short-lived ${ }^{123} \mathrm{I}$ and long live ${ }^{124}$ I(Artun and Aytekin, 2015) isotopes can be used as the diagnostic image in SPECT and PET. Besides, ${ }^{124} \mid$ allows for studying important organs such as the brain and heart (Alharbi \& Azzam, 2012). The long-lived ${ }^{125}$ I isotope also is used as a source for internal radiotherapy, bone dosimetry and a biological tracer (Skakun \& Qaim, 2008). Another iodine radionuclide ${ }^{122}$ | is a very short-lived isotope and used in PET for brain blood-flow studies(Qaim, 2004, Qaim, 2017).

During the last two decades, several semiclassical and quantum- mechanical models have been developed to treat the preequilibrium phase of reactions leading to the formation of the compound nucleus. The very first model is capable of reproducing the shapes of the continuous spectra (Griffin, 1966). He reported that "if one is willing to overlook the justification and retain the assumption of a binary collision even at lower energies, one can qualitatively explain some of the newly observed experimental features". He proposed the so-called statistical model of an intermediate structure, to explain the flat continuous part of the particle spectra.

Another complex but powerful model called the Fermi gas equilibration model was developed by Harp, Miller, and Berne in 1968 which is widely known as HMB model. In 1971, Blann proposed the so-called hybrid model by combining the advantageous aspect of both the HMB model and Griffin's model, thus making the new model most attractive and widely used of all the above formulations.

In 1973, Gadioli et al. improved and perfected the original Griffin's model into what is popularly known as the exciton model, equally successful as the hybrid model. The exciton and hybrid models are only special cases of a more general master equation approach originally proposed by Pauli in 1928. Generalizing this approach, Mantzouranis et al. in 1976 proposed a generalized exciton model, which had the additional capability of predicting angular distribution also.

Later in 1980, Ackermann et al. not only improved and refined this model but also proposed a random-walk model of preequilibrium decay which can describe multinucleon emission in the pre-equilibrium phase. Extending further the generalized exciton model, in 1979, Machner developed the exciton coalescence model, to account for complex particle emission in the preequilibrium phase as well as to predict their angular distributions. 
In 1987 Ernst et al. proposed the index model, projecting in the hybrid model the exact bookkeeping of the initial state densities as given in the unified model, and also incorporating multiple chance pre-equilibrium emission probability for nucleons (Rao \& Rao, 1991). The aim of this work is to calculate the reactions cross-section for proton-induced nuclear reactions on iodine-127 isotope and evaluated the excitation function using EXIFON code over a wide range of energies.

\section{Statistical Multistep Reaction}

Statistical multistep models are very successful in describing nuclear reactions at energies up to about $100 \mathrm{MeV}$. These models enable the description of direct, pre-equilibrium, and equilibrium processes in a consistent way for a wide mass number range and various reaction channels, e.g. neutrons, protons, alpha, and gamma particles.

The application of a statistical multistep model to heavy nuclei requires the consideration of fission as a competing process to particle and "gamma-ray emissions. Therefore, statistical

$$
\frac{d \sigma_{a, x b}^{M P E}\left(E_{a}\right)}{d E_{b}}=\sum_{c} \frac{d \sigma_{a, c b}\left(E_{a}\right)}{d E_{b}}+\sum_{c, d} \frac{d \sigma_{a, c d b}\left(E_{a}\right)}{d E_{b}}+\cdots
$$

\section{Activation Cross-Sections}

The following relations between the optical model (OM) reaction Cross-section and the energyintegrated partial Cross-sections should be satisfied (at each incident energy $\left(\mathrm{E}_{\mathrm{a}}\right)$ )

$$
\begin{aligned}
& \sigma_{\mathrm{a}}^{\mathrm{OM}}=\sum_{\mathrm{b}} \sigma_{\mathrm{a}, \mathrm{b}} \\
& \sigma_{\mathrm{a}, \mathrm{b}}=\sum_{\mathrm{c}} \sigma_{\mathrm{a}, \mathrm{cb}} \quad \text { and } \sigma_{\mathrm{a}, \mathrm{cb}}=\sum_{\mathrm{d}} \sigma_{\mathrm{a}, \mathrm{cdb}}
\end{aligned}
$$

with $\sigma_{a, b}=\sigma_{a, b}^{S M D}+\sigma_{a, b}^{S M C}$ the total first-chance emission, in this context, activation Cross-sections are given by

where $b, c, d \neq Y$

$$
\begin{aligned}
& \sigma_{a, b y}=\sigma_{a, b}-\sum_{c \neq \gamma} \sigma_{a, c b} \\
& \sigma_{a, c b \gamma}=\sigma_{a, c b}-\sum_{d \neq \gamma} \sigma_{a, c b d}
\end{aligned}
$$

For example, the $(n, p)$-activation Cross-sections have the form

$$
\sigma_{\mathrm{a}, \mathrm{p}}=\sigma_{\mathrm{n}, \mathrm{p}}-\sigma_{\mathrm{n}, \mathrm{pn}}-\sigma_{\mathrm{n}, 2 \mathrm{p}}-\sigma_{\mathrm{n}, \mathrm{pa}}
$$

The SMD Cross-section is a sum over s-step direct processes given by

$$
\frac{d \sigma_{a, b}^{S M D}\left(E_{a}\right)}{d E_{b}}=\sum_{s=1} \frac{d \sigma_{a, b}^{s}\left(E_{a}\right)}{d E_{b}}
$$

The SMD Cross-section has the form

$$
\frac{d \sigma_{a, b}^{S M C}\left(E_{a}\right)}{d E_{b}}=\sigma_{a}^{S M C}\left(E_{a}\right) \sum_{N=N_{0}}^{N^{I}} \frac{\tau_{N}(E)}{\hbar} \sum_{(\Delta V)} \Gamma_{N, b}^{(\Delta V)}\left(E, E_{b}\right) \uparrow \cdots
$$

where $\tau_{\mathrm{N}}$ satisfies the time-integrated master equation

and

$$
\begin{gathered}
-\hbar \delta_{\mathrm{NN}_{0}}=\Gamma_{\mathrm{N}-2}^{(+)}(\mathrm{E}) \downarrow \tau_{\mathrm{N}-2}(\mathrm{E})+ \\
\Gamma_{\mathrm{N}+2}^{(-)}(\mathrm{E}) \downarrow \tau_{\mathrm{N}+2}(\mathrm{E})-\Gamma_{\mathrm{N}}(\mathrm{E}) \tau_{\mathrm{N}}(\mathrm{E})
\end{gathered}
$$

$$
\Gamma_{N}^{(\Delta v)}(E) \downarrow=2 \pi I_{S S}^{2} \rho_{N}^{(\Delta v)}(E)
$$


The multiple particle emission is expressed as:

$$
\frac{d \sigma_{a, x b}^{M P E}\left(E_{a}\right)}{d E_{b}}=\sum_{c} \frac{d \sigma_{a, c b}\left(E_{a}\right)}{d E_{b}}+\sum_{c d} \frac{d \sigma_{a, c d b}\left(E_{a}\right)}{d E_{b}}+\cdots
$$

To keep the model tractable, a simple two-body interaction is assumed:

$$
\mathrm{I}\left(\mathrm{r}_{1}, \mathrm{r}_{2}\right)=-4 \pi \frac{\mathrm{F}_{0}}{\mathrm{~A}}\left[\mathrm{x}_{\mathrm{nl}}(\mathrm{R})\right]^{-4} \delta\left(\mathrm{r}_{1}-\mathrm{r}_{2}\right) \delta\left(\mathrm{r}_{1}-\mathrm{R}\right)
$$

$\mathrm{F}_{0}=27.5 \mathrm{MeV}$ taken from nuclear structure considerations(Qaim, 1986).

The factor $\left[x_{n l}(R)\right]^{-4}$ contains the wave function at the nuclear radius $R=r_{0} A^{1 / 3}$ The single-particle state density of particles $C=n, p$, a with mass $\mu_{c}$ is given by

$$
\begin{array}{r}
\rho\left(\mathrm{E}_{\mathrm{c}}\right)=\frac{4 \pi \mathrm{N} \mu_{\mathrm{c}}\left(2 \mu_{\mathrm{c}} \mathrm{E}_{\mathrm{c}}\right)^{1 / 2}}{(2 \pi \hbar)} \\
=\left(4.48 \times 10^{-3} \mathrm{fm}^{-3} \mathrm{MeV}^{-3 / 2}\right) \mathrm{r}_{0}{ }^{3} \mathrm{AE}_{\mathrm{C}}^{1 / 2}
\end{array}
$$

where $V=\frac{4 \pi R^{3}}{3}$ is equal to the nuclear volume (Ebiwonjumi, 2014).

The single-particle state density of bound particles (at Fermi energy) is then defined by

$$
\mathrm{g}=4 \rho\left(\mathrm{E}_{\mathrm{F}}\right)
$$

where factor 4 considers the spin and isospin degeneracy

\section{MATERIALS AND METHODS}

EXIFON code is a nuclear reaction software which provides a continuous and smooth description of nuclear reactions over a wide energy and mass range which is based on an analytical model for statistical multistep direct and multistep compound reactions (SMD/SMC model). It predicts emission spectra, angular distributions, and activation Cross-sections for neutrons, protons, alpha particles, and photons. Multiple particle emissions are considered for up to three decays of the compound system. EXIFON is a fast, easy-tohandle code which predicts Cross-sections from one global parameter set. The only adjustable quantity is the pairing shift. The INPEXI code creates input files for EXIFON2.0 from mass and shell-correction tables. The MAKE6 code transforms EXIFON output into an ENDF-6 format file.

The model is based on random matrix physics with the use of the Green's function formalism. All calculations are performed without any free parameters. Results were presented for bombarding energies below $30 \mathrm{MeV}$.

Procedure

Nuclear model calculations

Theoretical calculations of Cross-section were performed by nuclear model code EXIFON.
The input and target nucleus were defined and specify respectively and then the program was executed. The energy of incident particle was varying from $0 \mathrm{MeV}$ to $30 \mathrm{MeV}$. The cross section corresponds to each energy was obtained. The result of the cross section was used to determine the excitation functions of different reactions.

The output data (OUTEXI) for the calculation of cross-section was then stored in the set output directory. Secondly, the option without shell effect is also used for each target nucleus, also an output data (OUTEXI) for the calculation is then stored in the set output directory. Also, DAT file is stored in the set output directory.

\section{RESULTS AND DISCUSSIONS}

lodine-127 is a naturally occurring stable element with $100 \%$ abundance isotope of iodine when proton particle introduced into the nucleus, the nuclear reaction processes occurred and produced others stable and radioactive elements depending on the nature of incident particle energy. Table 1 shows the calculated cross-section data for protoninduced reactions on ${ }^{127} \mid$ for difference exits channels at different values of incident energy, the results were plotted in figure 1-4. 
Special Conference Edition, November, 2018

Table 1: The calculated cross-section data for proton-induced reactions on ${ }^{127} \mathrm{I}$ for difference exits channels

\begin{tabular}{|c|c|c|c|c|c|c|c|c|c|c|c|c|c|c|c|c|}
\hline $\begin{array}{l}\text { Ener } \\
\text { gy }\end{array}$ & $\begin{array}{c}(p, a \\
)\end{array}$ & $\begin{array}{c}(p, n \\
a)\end{array}$ & $\begin{array}{l}\text { (p,a } \\
\mathrm{g})\end{array}$ & $\begin{array}{c}(\mathrm{p}, \text { an } \\
)\end{array}$ & $\begin{array}{c}(p, g \\
)\end{array}$ & $\begin{array}{c}(\mathrm{p}, \mathrm{n} \\
\mathrm{g})\end{array}$ & $\begin{array}{l}\text { (p,p } \\
\text { g) }\end{array}$ & $\begin{array}{c}(p, 2 n \\
g)\end{array}$ & $(p, n)$ & $\begin{array}{c}(p, 2 n \\
)\end{array}$ & $\begin{array}{c}(p, p \\
n)\end{array}$ & $\begin{array}{c}(p, 3 n \\
)\end{array}$ & $\begin{array}{c}(p, p \\
)\end{array}$ & $\begin{array}{l}(p, n \\
p)\end{array}$ & $\begin{array}{c}(p, 2 \\
p)\end{array}$ & $\begin{array}{c}(p, 2 n \\
p)\end{array}$ \\
\hline 1 & 0 & 0 & 0 & 0 & 0 & 0 & 0 & 0 & 0 & 0 & 0 & 0 & 0 & 0 & 0 & 0 \\
\hline 2 & 0 & 0 & 0 & 0 & 0 & 0 & 0 & 0 & 0 & 0 & 0 & 0 & 0 & 0 & 0 & 0 \\
\hline 3 & 0 & 0 & 0 & 0 & 0 & 0 & 0 & 0 & 0 & 0 & 0 & 0 & 0 & 0 & 0 & 0 \\
\hline 4 & 0 & 0 & 0 & 0 & 0 & 0 & 0 & 0 & 0 & 0 & 0 & 0 & 0 & 0 & 0 & 0 \\
\hline 5 & 0 & 0 & 0 & 0 & 0.7 & 18.2 & 0 & 0 & 18.2 & 0 & 0 & 0 & 0 & 0 & 0 & 0 \\
\hline 6 & 0 & 0 & 0 & 0 & 1.2 & 67.1 & 0 & 0 & 67.1 & 0 & 0 & 0 & 0 & 0 & 0 & 0 \\
\hline 7 & 0 & 0 & 0 & 0 & 1.4 & $\begin{array}{c}138 . \\
6\end{array}$ & 6.8 & 0 & 138.6 & 0 & 0 & 0 & 6.8 & 0 & 0 & 0 \\
\hline 8 & 0 & 0 & 0 & 0 & 1.6 & 232 & 11.8 & 0 & 232 & 0 & 0 & 0 & 11.8 & 0 & 0 & 0 \\
\hline 9 & 0.1 & 0 & 0.1 & 0 & 1.7 & $\begin{array}{c}346 . \\
8\end{array}$ & 18.6 & 0 & 346.8 & 0 & 0 & 0 & 18.6 & 0 & 0 & 0 \\
\hline 10 & 0.3 & 0 & 0.3 & 0 & 1.9 & $\begin{array}{c}389 . \\
6\end{array}$ & 28.1 & 92.7 & 482.3 & 92.7 & 0 & 0 & 28.1 & 0 & 0 & 0 \\
\hline 11 & 0.6 & 0 & 0.6 & 0 & 2 & $\begin{array}{c}283 . \\
2\end{array}$ & 39.7 & 335.1 & 618.3 & 335.1 & 0 & 0 & 39.7 & 0 & 0 & 0 \\
\hline 12 & 1.1 & 0 & 1.1 & 0 & 2.1 & $\begin{array}{c}171 . \\
2\end{array}$ & 52 & 556.9 & 728.1 & 556.9 & 0 & 0 & 52.1 & 0 & 0 & 0 \\
\hline 13 & 1.8 & 0 & 1.8 & 0 & 2.1 & $\begin{array}{c}101 . \\
9\end{array}$ & 62.1 & 715.2 & 817.1 & 715.2 & 3.1 & 0 & 65.2 & 0 & 0 & 0 \\
\hline 14 & 2.6 & 0 & 2.6 & 0 & 2.2 & 65.9 & 67.5 & 823.5 & 889.5 & 823.5 & 11.8 & 0 & 79.2 & 0.1 & 0 & 0 \\
\hline 15 & 3.6 & 0 & 3.6 & 0 & 2.2 & 48.8 & 68.7 & 899.6 & 948.6 & 899.6 & 25.2 & 0 & 93.9 & 0.2 & 0 & 0 \\
\hline 16 & 4.7 & 0 & 4.4 & 0.3 & 2.2 & 41 & 71.7 & 955.3 & 996.7 & 955.3 & 37.7 & 0 & $\begin{array}{c}109 . \\
4\end{array}$ & 0.4 & 0 & 0 \\
\hline 17 & 5.9 & 0 & 5.1 & 0.8 & 2.3 & 37.7 & 76.5 & 997.3 & $\begin{array}{c}1035 . \\
8 \\
\end{array}$ & 997.3 & 49 & 0 & $\begin{array}{c}125 . \\
5\end{array}$ & 0.7 & 0 & 0 \\
\hline 18 & 7.2 & 0.1 & 5.8 & 1.4 & 2.3 & 36.4 & 82.6 & $\begin{array}{c}1029 . \\
5\end{array}$ & $\begin{array}{c}1067 . \\
1\end{array}$ & $\begin{array}{c}1029 . \\
5\end{array}$ & 59.7 & 0 & $\begin{array}{c}142 . \\
3\end{array}$ & 1.2 & 0 & 0 \\
\hline 19 & 8.5 & 0.1 & 6.3 & 2.2 & 2.3 & 36 & 89 & 995.4 & 1092 & $\begin{array}{c}1054 . \\
2 \\
\end{array}$ & 70.6 & 58.8 & $\begin{array}{c}159 . \\
6\end{array}$ & 1.7 & 0 & 0 \\
\hline 20 & 9.9 & 0.3 & 6.7 & 3.2 & 2.4 & 35.7 & 95.6 & 758.3 & $\begin{array}{c}1111 . \\
3\end{array}$ & 1073 & 81.8 & 314.7 & $\begin{array}{c}177 . \\
4\end{array}$ & 2.4 & 0 & 0 \\
\hline 21 & $\begin{array}{c}11 . \\
3\end{array}$ & 0.4 & 7.1 & 4.2 & 2.4 & 35.8 & $\begin{array}{c}101 . \\
9\end{array}$ & 468.4 & $\begin{array}{c}1125 . \\
8 \\
\end{array}$ & $\begin{array}{c}1086 . \\
5\end{array}$ & 93.8 & 618.1 & $\begin{array}{c}195 . \\
8\end{array}$ & 3.1 & 0 & 0 \\
\hline 22 & $\begin{array}{c}12 . \\
7\end{array}$ & 0.7 & 7.3 & 5.4 & 2.4 & 35.8 & $\begin{array}{c}107 . \\
7\end{array}$ & 262.9 & $\begin{array}{c}1136 . \\
1\end{array}$ & $\begin{array}{c}1095 . \\
7\end{array}$ & $\begin{array}{c}106 . \\
9\end{array}$ & 832.6 & $\begin{array}{c}214 . \\
6\end{array}$ & 4 & 0 & 0.2 \\
\hline 23 & $\begin{array}{c}14 . \\
1\end{array}$ & 1 & 7.4 & 6.7 & 2.5 & 35.9 & 115 & 144.1 & $\begin{array}{c}1142 . \\
7\end{array}$ & 1101 & $\begin{array}{c}118 . \\
9\end{array}$ & 956.3 & 234 & 4.9 & 0 & 0.6 \\
\hline 24 & $\begin{array}{c}15 . \\
6\end{array}$ & 1.3 & 7.5 & 8.1 & 2.5 & 36.9 & $\begin{array}{c}119 . \\
9\end{array}$ & 80.2 & 1146 & $\begin{array}{c}1101 . \\
8 \\
\end{array}$ & $\begin{array}{c}133 . \\
9\end{array}$ & $\begin{array}{c}1020 . \\
4\end{array}$ & $\begin{array}{c}253 . \\
8 \\
\end{array}$ & 6 & 0 & 1.2 \\
\hline 25 & 17 & 1.7 & 7.4 & 9.6 & 2.5 & 36.9 & $\begin{array}{c}124 . \\
3\end{array}$ & 47.2 & $\begin{array}{c}1146 . \\
3\end{array}$ & $\begin{array}{c}1100 . \\
6\end{array}$ & $\begin{array}{c}149 . \\
8\end{array}$ & $\begin{array}{c}1051 \\
4\end{array}$ & $\begin{array}{c}274 . \\
2\end{array}$ & 7.1 & 0.1 & 1.9 \\
\hline 26 & $\begin{array}{c}18 . \\
5\end{array}$ & 2.2 & 7.4 & 11.1 & 2.6 & 36.9 & 126 & 29.2 & $\begin{array}{c}1145 . \\
9\end{array}$ & $\begin{array}{c}1098 . \\
6\end{array}$ & $\begin{array}{c}166 . \\
9\end{array}$ & $\begin{array}{c}1066 . \\
4\end{array}$ & 293 & 8.3 & 0.1 & 2.8 \\
\hline 27 & $\begin{array}{c}19 . \\
9\end{array}$ & 2.8 & 7.3 & 12.6 & 2.6 & 36.8 & $\begin{array}{c}129 . \\
5\end{array}$ & 19.4 & $\begin{array}{c}1141 . \\
1\end{array}$ & 1092 & $\begin{array}{c}184 . \\
8\end{array}$ & $\begin{array}{c}1068 . \\
5\end{array}$ & $\begin{array}{c}314 . \\
5\end{array}$ & 9.5 & 0.1 & 3.9 \\
\hline 28 & $\begin{array}{c}21 . \\
3\end{array}$ & 3.4 & 7.1 & 14.1 & 2.6 & 36.7 & $\begin{array}{c}132 . \\
7\end{array}$ & 13.7 & $\begin{array}{c}1133 . \\
9\end{array}$ & $\begin{array}{c}1083 . \\
1\end{array}$ & $\begin{array}{c}203 . \\
7\end{array}$ & $\begin{array}{c}1063 . \\
9\end{array}$ & $\begin{array}{c}336 . \\
5\end{array}$ & 10.8 & 0.2 & 5 \\
\hline 29 & $\begin{array}{c}22 . \\
6\end{array}$ & 4 & 7 & 15.6 & 2.7 & 36.5 & $\begin{array}{c}135 . \\
5\end{array}$ & 10.3 & $\begin{array}{c}1124 . \\
6\end{array}$ & $\begin{array}{c}1072 . \\
1\end{array}$ & $\begin{array}{c}223 . \\
4\end{array}$ & $\begin{array}{c}1054 . \\
8\end{array}$ & $\begin{array}{c}359 . \\
1\end{array}$ & 12.1 & 0.2 & 6.2 \\
\hline 30 & $\begin{array}{c}23 . \\
9\end{array}$ & 4.6 & 6.8 & 17 & 2.7 & 36.4 & 138 & 8.1 & $\begin{array}{c}1113 . \\
5\end{array}$ & $\begin{array}{c}1059 . \\
1\end{array}$ & $\begin{array}{c}243 . \\
9\end{array}$ & $\begin{array}{c}1042 . \\
5\end{array}$ & $\begin{array}{c}382 . \\
3\end{array}$ & 13.4 & 0.3 & 7.5 \\
\hline
\end{tabular}




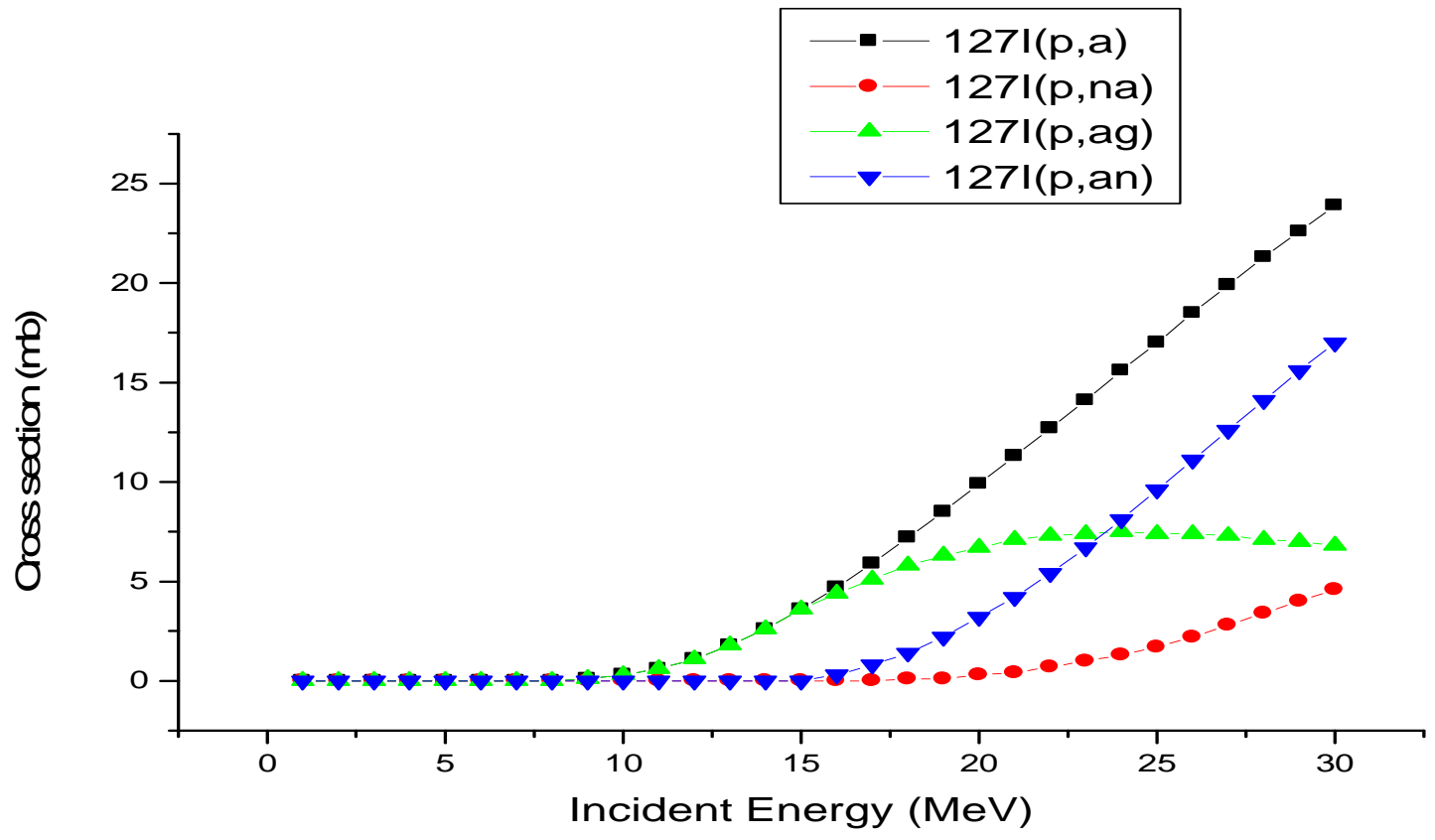

Figure 1. Graph of Cross section against incident energy

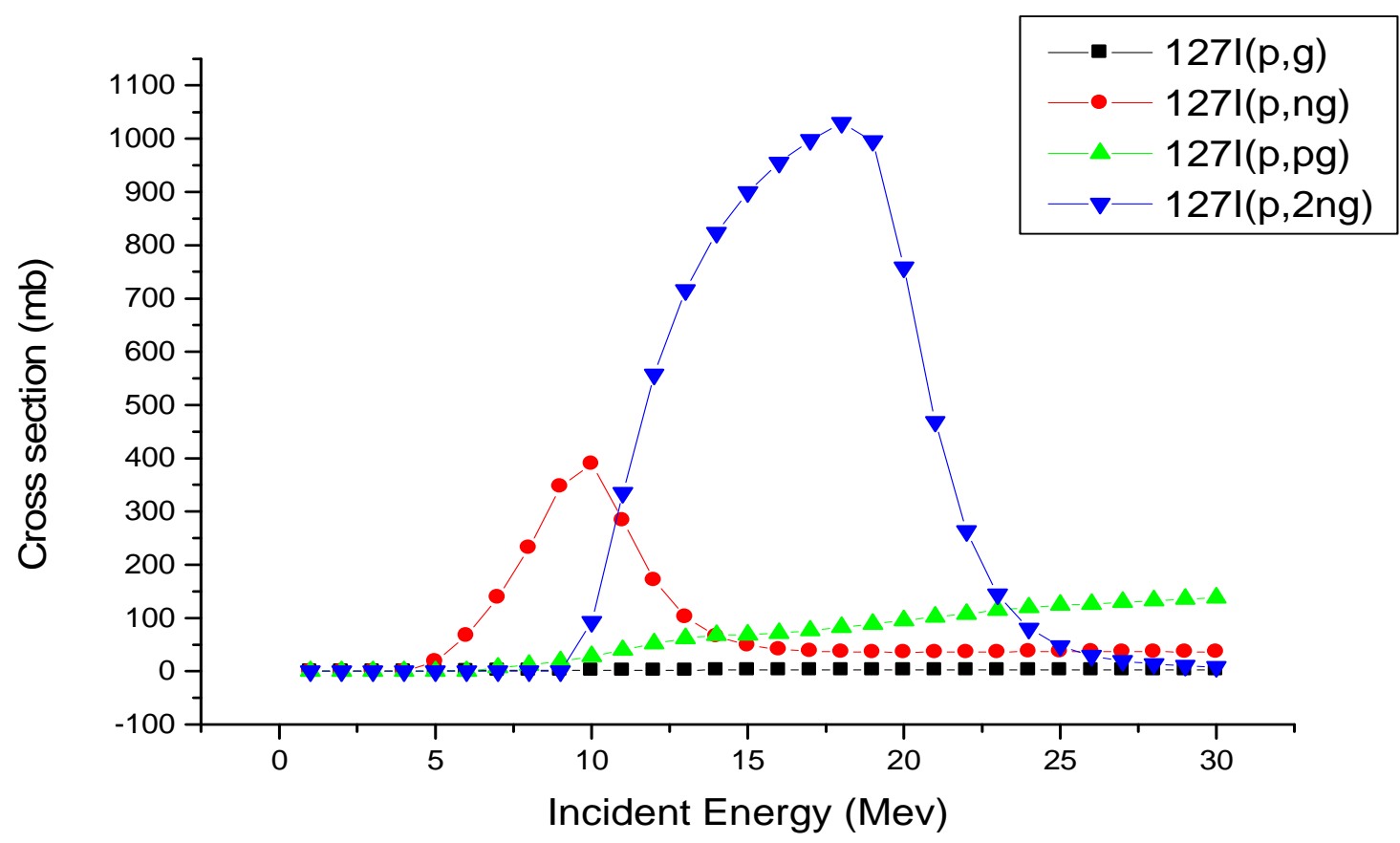

Figure 2. Graph of Cross section against incident energy 


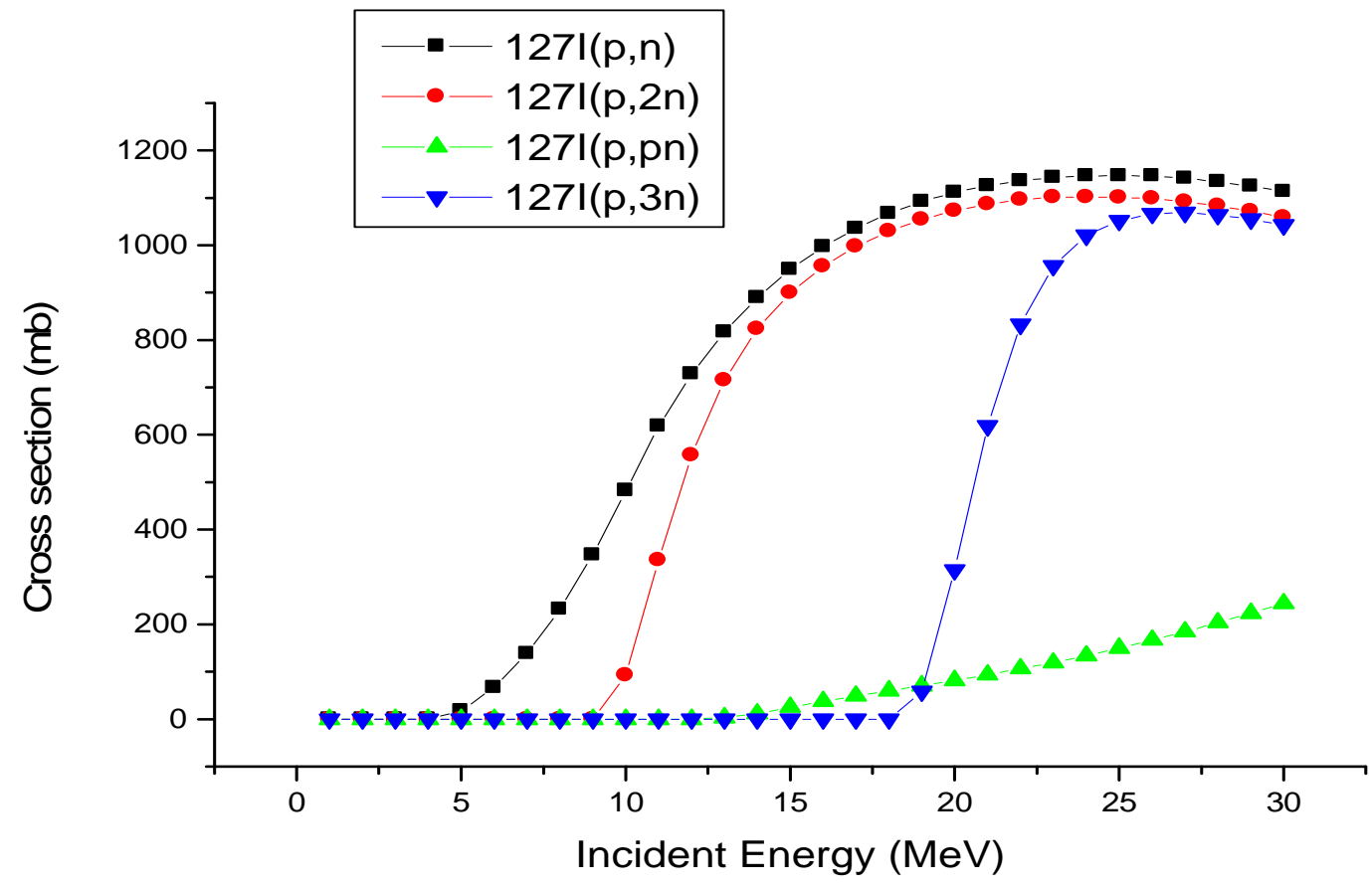

Figure 3. Graph of Cross section against incident energy

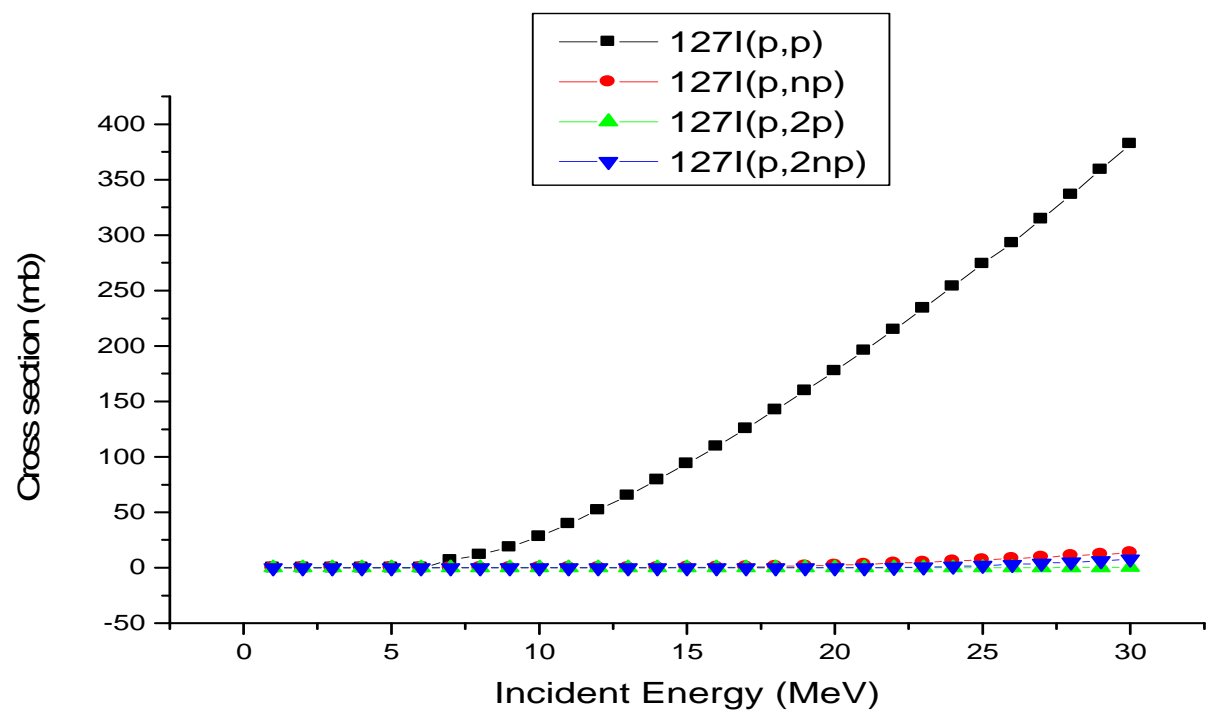

Figure 4. Graph of Cross section against incident energy

\section{DISCUSSION}

Figure 1 shows the Graph of Cross section against incident energy for the production of tellurium isotopes, the reaction ${ }^{127} I(p, a){ }^{126} \mathrm{Tl}$ is a pick up the reaction which shows that when proton interact with lodine(127), it produces Tellurium(126) isotope. The reaction ${ }^{127} I(p, n a)^{125} T l$ shows the production of Tellurium (125) isotope. The reaction ${ }^{127} I(p, a g){ }^{126} \mathrm{Tl}$ shows the production of Tellurium (126) isotope at the excited state.
The reaction ${ }^{127} I(p$, an $){ }^{126} T l \rightarrow{ }^{125} T l+n$ shows the production of Tellurium (125) isotope through the excited state of Tellurium(126).

In Figure 2, the reaction ${ }^{127} I(p, p g){ }^{127} I$ is an inelastic scattering between the incident particle which is proton and iodine(127) nucleus, where some energy of the incident particle was transferred to target nucleus that makes it excite and de-excite through gamma emission. The other three graphs in figure 2 show the production of Xenon isotopes. 
Special Conference Edition, November, 2018

The reaction ${ }^{127} I(p, g){ }^{128} \mathrm{Xe}$ is excitation function for the production Xenon(128) isotope. The reaction ${ }^{127} I(p, n g)^{127} \mathrm{Xe}$ is excitation function for the production Xenon (127) isotope. The reaction ${ }^{127} I(p, 2 n g){ }^{126} X e$ is excitation function for the production Xenon (126) isotope.

In Figure 3 , the reaction ${ }^{127} I(p, p n)^{126} I$ is a pickup reaction, where the incident particle kick out one nucleon from the target nucleus that makes it lodine (126) isotope. The other three graphs in figure 3 show the production of Xenon isotopes. The reaction ${ }^{127} I(p, n){ }^{127} \mathrm{Xe}$ is an excitation function for the production Xenon (127) isotope. The reaction ${ }^{127} I(p, 2 n){ }^{126} \mathrm{Xe}$ is an excitation function for the production Xenon(126) isotope. The reaction ${ }^{127} I(p, 3 n){ }^{125} \mathrm{Xe}$ is an excitation function for the production Xenon(125) isotope.

Figure 4, the reaction ${ }^{127} I(p, p)^{127} I$ is an elastic scattering between the target nucleus of lodine (127) and incident particle proton. The reaction ${ }^{127} I(p, n p){ }^{126} I$ is excitation function for the production lodine (126) isotope. The reaction ${ }^{127} I(p, 2 n p)^{125} I$ is excitation function for the production lodine (125) isotope. The reaction

\section{REFERENCES}

Ahmad, I., \& Koki, F. S. (2017). Calculation of Reactions Cross Section for NeutronInduced Reactions on 127 I Isotope, Int. J. Med. Physics, Clin. Eng. Radiat. Oncol., 344-359.

https: //doi.org/10.4236/ijmpcero.2017.6 3031

Ahmad, I., Yola, Y. I., \& Koki, F. S. (2017). Evaluation of Excitation Functions of Reactions Used in Production of Some Medical Radioisotopes, Int. J. Med. Physics, Clin. Eng. Radiat. Oncol.,290303.

https: / /doi.org/10.4236/ijmpcero.2017.6 3026

Alharbi, A. A., \& Azzam, A. (2012). Theoretical calculations of the reaction cross-sections for proton-induced reactions on natural copper using ALICE-IPPE code. Applied Radiation and Isotopes, 70(1), 88-98. https://doi.org/10.1016/j.apradiso. 2011. 09.009

Artun, O., \& Aytekin, H. (2015). Calculation of excitation functions of a proton, alpha, and deuteron induced reactions for the production of medical radioisotopes 122 125I. Nuclear Instruments and Methods in Physics Research, Section B: Beam Interactions with Materials and Atoms, 345, 1-8. https: //doi.org/10.1016/j.nimb.2014.12. 029
${ }^{127} I(p, 2 p){ }^{126} \mathrm{Tl}$ is a pick up a reaction, where the incident particle kick out one nucleon from the target nucleus that makes it Tellurium(126) isotope.

\section{CONCLUSION}

For optimum production and internal application of radionuclides nuclear data are very important. In this work, the nuclear reaction cross sections data was calculated and investigation of the excitation functions for the formation of $127,126,125 \mathrm{I},{ }^{126,127,128} \mathrm{Xe},{ }^{126,125} \mathrm{Te}$ isotopes was evaluated, in the interactions of incident particle "proton" with the nucleus of the iodine-127 isotope. The results analysis confirmed the variations of nuclear interaction cross-section with a variation of energy of the incident particle. In figure 2 one can see that the plots of the reactions ${ }^{127} I(p, n g){ }^{127} X e$ and ${ }^{127} I(p, 2 n g){ }^{126} X e$ have full excitation curve, this confirmed that the production of Xenon (127) and Xenon (126) isotopes are possible at the energy range of 0 to $30 \mathrm{MeV}$.

These findings can be served as additional information regarding nuclear data for the above mention isotopes of tellurium, Xenon, and iodine.

Ebiwonjumi, Y. E. C. B. F. (2014). Determination of Nuclear Reaction Cross-sections for Neutron- Induced Reactions in Some Odd - A Nuclides, 32, 55-69.

Kalka, H. (1992). Hadrons and Nuclei Statistical multistep reactions from 1 to $100 \mathrm{MeV}$. Zeitschrift Fur, Physik A, 299, 289-299.

Qaim, S. M. (1986). A study of $(n, n a)$ reaction cross section at $14.7 \mathrm{MeV}$. NUCL. PHYS. A, 458(2), 237-245.

Qaim, S. M.(2017) Nuclear data for medical applications: An overview of present

status and future need, EPJ Web of Conferences 146, $08001 \quad$ DOI: 10.1051 /epjconf / 201714608001 ND2016pp1-5

Qaim, S. M. (2004). Use of cyclotrons in medicine. Radiation Physics and Chemistry, 71, 917926. https: / /doi.org/10.1016/j.radphyschem. 2004.04.124

Rao, A. V. M., \& Rao, J. R. (1991). PreEquilibrium Analysis of the Excitation Functions of $(\mathrm{a}, \mathrm{xn})$ Reactions on Silver and Holmium. Il Nuovo Cimento, 104(6), 863-874.

Skakun, Y., \& Qaim, S. M. (2008). Measurement of excitation functions of helion-induced reactions on enriched $\mathrm{Ru}$ targets for production of medically important 103Pd and $101 \mathrm{mRh}$ and some other radionuclides. Applied Radiation and Isotopes, 66(5), 653-667. https: //doi.org/10.1016/j.apradiso. 2007. 11.013 